a certain 'facies,' that is to say, each possessing different ecological habits.

Further particulars about the ecological habits, geographical distribution and life history of the crawfishes mentioned above will be given in my memoir on the crawfishes of the state of Pennsylvania, which is now ready for publication.

A. E. Ortmann.

Carnegie Museum,

Pittsburg, Pa., March 1, 1906.

\section{FACTORS OF SPECIES-FORMATION.}

To the Editor of Science: The short note by Dr. Ortmann in Science of January 12, 1906, no less than the larger work of Gulick to which he refers, as well as much of the recent discussion of isolation as an evolutionary factor, are all rich in illustrations of the need of a simple distinction.

Unfortunately for the progress of evolutionary science among his contemporaries and immediate successors, Darwin began the title of his first book on evolution with the fateful words, 'The Origin of Species.' Around this ark of a new biological covenant the chosen people of science have waged fifty years of sanguinary warfare, and it is now a very ungracious task to convince them that the species-origination box never did contain the sacred relics of evolution. But if science is to seek truth rather than tradition, we may not close our eyes to the perception that the factors of species-formation are not at all factors of evolution.

Questions of species-formation are generally debated because of interest in evolution, though for purposes of scientific study and explanation the two lines of investigation are as completely distinct as gravitation and hydrostatics. Isolation, in one form or another, ${ }^{1}$

'See Ortmann, 'Crustaceen' in Semon, Zool. Forschungsreisen in Australien, etc., Jenaisch. Denkschr., 8, 1894, p. 67; and Ortmann in 'Bronn's Klass und Ordn. d. Tierreichs.,' 5, 2, 1899, p. 1,202.

${ }^{1}$ Chronological isolation may be quite as effective for species-formation as separation in space, and permits species of common origin to become diverse while still occupying the same region. Many plants and insects, of tropical as well as of temperate regions, have their flowering times or is an indispensable factor in the subdivision of species, but to evolution it contributes nothing whatever. Isolation may sometimes retard or prevent evolution, 'but it is not an evolutionary factor except in a minor and negative sense. ${ }^{2}$ The two groups of phenomena belong to entirely different categories; stirring them together only keeps the emulsion from clarifying into the two component solutions.

Evolution is a process of organic change and development, universal and continuous, and due to causes resident in species. Speciation, to give the other process a name, is the origination or multiplication of species by subdivision, usually, if not always, as a result of environmental incidents. Speciation is thus an occasional phenomenon which does not cause evolution, and is not caused by evolution. One procession of organisms may be divided into two, but it does not appear that the new groups will travel in any different manner than before, nor that they will go any faster or any farther than if they had not been separated. The subdivision enables the two parts to follow different roads and to arrive at different destinations, but it does not assist the evolutionary locomotion nor give us any clue as to how it is accomplished. The evolutionary interest of isolation is that each case affords additional evidence of continuous, progressive change as the normal evolutionary condition of all groups of interbreeding organisms. The isolation of a new group is an interesting biological event, a crisis, as it were, in speciation, but it gives us no special opportunities of studying the causes of evolution. Perception of these elementary facts would have saved the writing of many books, and breeding seasons restricted to annual occasions of extremely short duration. In some groups a considerable series of years may intervene between periods of propagation, as in the bamboos and periodical cicadas.

${ }^{2}$ A more extended presentation of this distinction is to be found in 'Evolution Not the Origin of Species,' Popular Science Monthly, March, 1904. The paper was reprinted in revised and extended form in the Smithsonian Report for 1904, pp. 397-412, under the title 'The Evolutionary Significance of Species.' 
many unprofitable controversies. General theories of evolution are not to be established on speciation, either by natural selection, isolation or mutation.

Gravitation furnishes what might be called a background for hydrostatics, and evolution, in a similar way, makes speciation possible. Isolated groups of organic individuals always become different. The vital equilibrium of specific bodies of organisms is sustained by interbreeding and evolutionary motion. Analogies of physical phenomena of rest and inertia do not apply. To hold organic types uniform and stationary by selection has been attempted many times, but degeneration promptly ensues. Diversity and change are not the results of special evolutionary causes acting at rare intervals of species-formation, but are the normal and necessary conditions of organic existence.

To understand species-formation, evolution must be taken for granted, as an Irishman might say, and as many savants of other nationalities have unconsciously written. If we are interested merely in the positional relations of the automobile, it is enough to know that the handle can be turned and that the wheels go round. Our progress can then be nicely explained by a few properly selected factors, such as: (1) Wheel-turning (continued, inherited 'variation'); (2) roads to travel (by selection); (3) handle-turning (accommodation), to steer around corners and mud-holes. But to ask how the machine was constructed, how the handle turns it, and how the wheels happen to revolve, are bothersome questions of details with which taxonomic observers of automobiles do not need to concern themselves. Species travel because they - are built that way, not because the environment pushes them. ${ }^{3} \quad$ Each species is equipped on the inside with the factors of its own evolu-

\footnotetext{
${ }^{3}$ Darwin and some of his followers appear to have tacitly assumed what might be termed a specific constant of variability, so that natural selection by shearing off one side of the species could compel the other side to grow out, and thus roll the species along. How isolation could serve as an evolutionary factor seems not to have been indicated.
}

tion, such as heterism, symbasis and mitapsis, for maintaining the normal individual diversity and the broad network of descent which are requisite for sustained organic effciency and evolutionary progress." But all this is another story. The factors of speciesformation afford very interesting matters of discussion, but let us not confuse ourselves further by imagining that they are factors of evolution.

Washington, D. C., January 27, 1906.

\section{SPECIAL ARTICLES.}

THE POSSIBILITY OF PSYCHICAL FACTORS IN ILLUSIONS OF REVERSED MOTION.

ONE of the most interesting chapters in psychological optics is concerned with what have been variously termed 'after-images of motion,' ' antirheoscopic phenomena,' 'subjective complementary movements,' or 'illusions of reversed motion,' These illusions are quite easily observed, $e$. g., by fixating a rotating disc on which a heavy spiral line has been traced, or a rotating drum on which lines have been drawn at right angles to the direction of movement, or by watching the landscape from the window of a moving train or the waves of a stream from its bank. A very pretty demonstration (the 'water-fall illusion,' first described by Addam in 1834) may be secured by fixating for a half-minute some convenient mark seen through the falling spray of a water-fall, and then transferring the gaze to a neighboring cliff, which will promptly 'flow' upward in a most striking manner. Indeed, some observers experience all the unpleasantness of a vertigo from this simple experiment, and several writers relate the two phenomena by giving similar theoretical explanations.

These illusions of reversed motion have been under observation from time to time since the first published account by Purkinje in 1825, and have been experimentally examined in numerous ingenious ways, first by Plateau in

. “Evolution of Cellular Structures,' Bull. 81, Bureau of Plant Industry, U. S. Department of Agriculture. 